\title{
Characterization of $\beta$-lactoglobulin from buffalo (Bubalus bubalis) colostrum and its possible interaction with erythrocyte lipocalin-interacting membrane receptor
}

\author{
Received February 18, 2011; accepted April 1, 2011; published online May 4, 2011
}

\section{Rohit A. Chougule and Huligerepura S. Aparna*}

Department of Studies in Biotechnology, University of Mysore, Manasagangotri, Mysore 570 006, Karnataka, India

*Dr H.S. Aparna, Department of Studies in Biotechnology, University of Mysore, Mysore- 570 006, Karnataka, India. Tel: 91-821-2419883, Fax: 91-821-2419363,

email: hsa.uom@gmail.com

Lipocalins form a widespread class of proteins involved in the transport of weakly soluble vitamins, hormones or hydrophobic molecules. $\beta$-lactoglobulin (BLG-col), a major lipocalin present in whey was purified and characterized from buffalo colostrum. The molecular weight of BLG-col as determined by Liquid chromatography -electrospray ionization mass spectrometry (LC-ESIMS) was $18.257 \mathrm{kDa}$ and the peptide mass fingerprint of the purified protein revealed $67 \%$ sequence homology to buffalo milk $\beta$-lg. The N-terminal-IIVTQ and LC-ESI-collision-induced dissociation-Electron transfer dissociation mass spectrometry/mass spectrometry analyses of doubly $\left(m / z, 1156^{+2}\right)$ and triply $\left(m / z 546^{+3}\right)$ charged ion pairs corresponding to VYVEELKPTPEGDLEILLQK (41-60) and TPEV DDEALEKFDK (125-138) sequences confirmed the identity of BLG-col. Using these peptide sequences, the location of a gene encoding for BLG-col was identified on chromosome 11 at $11 q 28$ loci of bovine genome. The unique property of the BLG-col isolated from buffalo colostrum was its strong and specific haemagglutinating activity with ' $O$ ' blood of human erythrocytes with $10,309 \mathrm{HAU} / \mathrm{mg}$ protein. The cell surface localization of BLG-col on human erythrocytes was confirmed by immunocytochemistry and the specificity of interaction was established by immunoblot analysis of human erythrocyte membrane proteins. Based on these observations, we suggest the presence of lipocalin receptor $(70 \mathrm{kDa})$ on human erythrocyte membrane and the multiple sequence alignment supported structural diversity among lipocalin receptors.

Keywords: Bubalus bubalis/colostrum/ $\beta$-lactoglobulin/ immunoblot/lipocalin/mass spectrometry.

Abbreviations: DHB, 2, 5-Dihydroxybenzoic acid; FITC, fluorescein isothiocyanate; PMF, peptide mass fingerprint; PVDF, polyvinylidene fluoride;

LC-ESI-CID/ETD MS/MS, Liquid

Chromatography-Electro Spray Ionization-Collision Induced Dissociation/Electron Transfer Dissociation Mass Spectrometry/Mass Spectrometry.
Colostrum, nature's specially designed food for neonates, is a complex biological fluid containing glycoconjugates, growth and tissue repair factors, phagocytes and array of bacteriostatic and antiviral defence factors along with normal components of mature milk (1). The immune-boosting property of colostrum stems from various bioactive molecules in conjunction with cellular components protects not only the maternal mammary gland but also the recipient infant from various infections. The macromolecules are often resistant to enzymatic digestion in the gastrointestinal tract and inhibit the localized adherence of enteropathogens to the digestive tract of neonates (2). Thus, glycoconjugates and bioactive peptides isolated from bovine colostrum are extensively used as neutraceuticals in infant food and formula (3).

On a global scale, buffalo is a major milking mammal of Asia. Buffalo milk has almost $11.42 \%$ more protein content compared with bovine milk (4), and the protein content is even higher in the colostrum (5). During our previous investigations on buffalo colostrum glycoconjugates, we have identified antigenic glycopeptides (6) and macrophage activating oligosaccharides (7) similar to those present in bovine and human colostrum. Further, presence of bifidogenic glycoproteins in colostral whey (8) in analogy to human colostrum whey proteins demonstrated the immunoprotective role of the colostrum glycoconjugates. Hence, both buffalo milk and colostrum can be used as alternatives to bovine milk products for the isolation of probiotics.

The colostrum whey proteins comprise $35 \%$ of the total milk proteins and are rich in $\beta$-lactoglobulin, $\alpha$-lactalbumin, glycomacropeptides, albumin, proteose peptone-3 and immunoglobulins and their immunoregulatory activities have been well documented by both in vivo and in vitro studies $(9,10)$.

$\beta$-lactoglobulin is the most abundant whey protein, which belongs to lipocalin family of proteins (11). Lipocalins are a large group of extracellular proteins that show great diversity in their sequences and molecular recognition properties. The members of the lipocalin family of proteins play pivotal roles in the transport of small hydrophobic molecules, colouration, olfaction, prostaglandin synthesis, cell homoeostasis and immunomodulation (12). Recent evidences suggest the functional advantage of $\beta-\lg$ in the transport of vitamin D and indicated that supplementation of milk with vitamin D effectively enhanced its uptake (13). The peptides derived from $\beta$-lactoglobulin have attracted considerable attention due to their 
antihypertensive, antimicrobial, antioxidant, opioid, hypocholesterolaemic and immunostimulatory properties (14). The high nutritional and functional value of $\beta$-lg has therefore made it a choice food ingredient in the formulation of modern food supplement, BioZate (15). The sequence homology between $\beta$-lactoglobulin and glycodelin, which is found in the human endometrium during pregnancy (16), further substantiates its role in transferring passive immunity to neonates.

The well-studied lipocalin-interacting membrane proteins includes retinol binding protein (RBP; STRA6), lipocalin-1 (Lcn-1) and megalin. The STRA6 receptor being present on the cell surface promotes transport of retinol as retinoid cannot be synthesized de novo while, Lcn-1 present in wide variety of organisms is known to bind large array of hydrophobic ligands. However, megalin is an endocytic receptor, which includes mouse RBP, mouse urinary protein, mouse odorant binding protein, apolipoprotein $M$ and human Lcn-2. There are clear evidences for a specific receptor for $\beta$-lactoglobulin on the intestine of calf neonates, bovine germ cell plasma membranes and transformed mammalian cells (17) and a recent report suggests LIMR-mediated cellular internalization of $\beta$-lactoglobulin in NT2 cells (18).

Surprisingly, $\beta$-lactoglobulin has been isolated from bovine (19), ovine (20), caprine (21) and buffalo milk (22) but not from colostrum. The functional properties of $\beta$-lactoglobulin are well ascribed from bovine milk (14) and hence there is ample opportunity to perform a comparative analysis of $\beta$-lactoglobulin from different sources. In the present study, we have purified, characterized and determined haemagglutinating activity (HAU) of $\beta$-lactoglobulin from buffalo colostrum. Furthermore, based on immunocytochemistry, immunoblot and MS analyses, we suggest the possible presence of lipocalin receptor on human red blood corpuscles.

\section{Materials and Methods}

\section{Isolation and purification of whey proteins}

The whey proteins were isolated from buffalo colostrum as described earlier (8). The purification of whey proteins was achieved by ammonium sulphate fractionation followed by gel permeation chromatography on Sephadex G-100.

\section{LC-ESI-MS analysis of intact protein}

LC-ESI-MS separation of intact BLG-col was carried out on HP1100 (Agilent) on a C-8 reverse-phase column $(4.6 \times 150 \mathrm{~mm}$; ZORBAX RX-C8, $5 \mu \mathrm{m}$, Agilent). The solvent system consisted of $0.1 \%$ formic acid (A) and acetonitrile containing $0.1 \%$ formic acid (B). The protein was separated using a linear gradient of $10 \%$ solvent B-95\% solvent B in $35 \mathrm{~min}$ at a flow rate of $0.2 \mathrm{ml} / \mathrm{min}$. Mass spectrum was acquired in positive ion mode by scanning $m / z$-range from 400 to 2,800 . The data was analysed using Data analysis 4.0 software.

\section{N-terminal amino acid analysis}

Protein $(30 \mu \mathrm{g})$ was electrophoresed on an Sodium dodecyl sulphate polyacrylamide gel electrophoresis (SDS-PAGE) (15\%) gel and electroblotted onto a polyvinylidene fluoride (PVDF) membrane by a semidry procedure using Tris-glycine buffer $\mathrm{pH} 10$ containing methanol $(20 \%)$ and SDS $(0.1 \%)$. The membrane was stained with Coomassie brilliant blue R-250 and destained in methanol $(50 \%)$ until the protein bands were visible. The membrane was then washed extensively in water, and the band of interest was excised for N-terminal amino acid analysis by Edman degradation using 4-dimethyl-aminoazobenzene isothiocyanate (23) and analysed by protein sequencer (Applied Biosystems, USA).

\section{Multiple sequence alignment}

The N-terminal sequence of BLG-col derived from amino acid analysis was compared using ClustalW2 (http:/www.ebi.ac.uk/Tools/ msa/clustalw2/) online server with the N-terminal sequences of ruminant and other mammalian species acquired from UniProt Database.

\section{Enzymatic digestion}

The protein bands stained with Coomassie blue were excised from SDS-PAGE and subjected for in-gel trypsin digestion (24). Briefly, the excised gel was crushed in to small pieces, transferred to sterile siliconized eppendorff and destained by repeated washing with $50 \mathrm{mM} \mathrm{NH} \mathrm{NHCO}_{3}$. The gel pieces were rehydrated in DTT $(10 \mathrm{mM})$, ammonium bicarbonate $(100 \mathrm{mM}, 30 \mathrm{~min})$ and alkylated with iodoacetamide $(50 \mathrm{mM})$ in ammonium bicarbonate $(100 \mathrm{mM})$. The sample was dehydrated using acetonitrile and dried by speedvac. Enzymatic digestion was carried out by incubating the dried gel pieces overnight with trypsin (Promega Porcine trypsin, $20 \mu \mathrm{l}$ of $20 \mathrm{ng} / \mu \mathrm{l}$ stock solution containing $50 \mathrm{mM}$ of $\mathrm{NH}_{4} \mathrm{HCO}_{3}$ ) at $37^{\circ} \mathrm{C}$ The tryptic peptides were extracted from gel using $50 \%$ acetonitrile containing $1 \%$ Trifluoroacetic acid (TFA). The extraction step was repeated 3-4 times using fresh extraction solution and the pooled peptides were dried in a speed-vac.

\section{Matrix Assisted Laser Desorption lonization-Time of Flight-Mass Spectrometry (MALDI - TOF - MS) analysis}

The MALDI-MS spectra of the analyte was acquired on a Bruker Daltonics ULTRAFLEX TOF-TOF instrument equipped with a pulsed N2 laser, and analysed in the reflectron mode using a $90 \mathrm{~ns}$ time delay, and a $25 \mathrm{kV}$ accelerating voltage in the positive ion mode. External calibration was done to a spectrum acquired for a mixture of peptides with masses ranging from 757 to $3,147 \mathrm{Da}$ (peptide mixII P.No-222570). The analyte $(0.5 \mu \mathrm{l})$ was mixed with an equal volume of 2, 5-Dihydroxybenzoic acid $(0.5 \mu \mathrm{l}, 20 \mathrm{mg} / \mathrm{ml}$ in $50 \%$ acetonitrile containing $0.1 \%$ trifluoroacetic acid) on a MALDI plate, and spectra were recorded in the positive ion mode using the Bruker Daltonics FLEX control software.

\section{LC-CID/ETD-MS/MS analysis}

HPLC workflow was performed on an Agilent (HP1100 Series) with detection at $226 \mathrm{~nm}$. The tryptic peptides were separated on C-18 column $(4.6 \times 150 \mathrm{~mm}$; ZORBAX RX-C18, $5 \mu \mathrm{m}$, Agilent $)$ using a linear gradient of acetonitrile containing $0.1 \%$ formic acid $(5-95 \%)$ in $55 \mathrm{~min}$ at a flow rate of $200 \mu \mathrm{l} / \mathrm{min}$. LC was interfaced directly with a ion trap (HCT ULTRA ETD II, Bruker Daltonics, Germany) mass spectrometer equipped with two octapole followed by an ion trap and a separate hexapole next to negative chemical ionization chamber. The ESI MS/MS data of the tryptic peptides were obtained for both CID and ETD, excluding singly charged ions. Helium gas was used as the collision gas for CID experiments. Fluoranthene was used as the electron transfer reagent and methane was used for the chemical ionization (25). The reaction time of electron transfer was typically set at $100 \mathrm{~ms}$ with the following parameters: compound stability $100 \%$, with maximum output of ETD reagent ion $202 \mathrm{~m}$ $z$, scan range $100-2,800 \mathrm{~m} / z$, target mass of $900 \mathrm{~m} / z$ and reagent ion ICC was set to 200,000

\section{Database search}

MALDI-TOF MS data of tryptic digest was searched using MASCOT PMF (http://www.matrixscience.com/cgi/search form .pl?FORMVER $=2 \&$ SEARCH $=$ PMF) and PROWL Peptide Map on-line search engines (http://prowl.rockefeller.edu/prowl/peptidemap.html). For the database search, carbamidomethylation of cysteines as fixed and oxidation of methionine as variable modifications were used. In the search programme, one missed tryptic cleavage was accepted and a mass tolerance of $0.6 \mathrm{Da}$ was set for both precursor ion and fragment ion masses.

The CID-MS/MS data were processed using Data analysis software, version 4.0 and. $\mathrm{mgf}$ file extracted from data analysis software was analysed by Mascot MS/MS ion search database. De novo sequencing of the peptide tags obtained from Mascot database 
search was carried out by submitting the sequences to PFIA software to deduce theoretical $\mathrm{b}$ and $\mathrm{y} / \mathrm{c}$ and $\mathrm{z}$ ion fragmentation pattern and the same was compared with the CID/ETD MS/MS spectra.

\section{Haemagglutination assay}

Human blood samples were obtained from University hospital donated by healthy volunteers. Human erythrocytes suspended in phosphate buffer saline (PBS; $100 \mathrm{mM}, \mathrm{pH} 7.2$ ) were centrifuged $(3,000 \mathrm{rpm}, 10 \mathrm{~min})$, and the pellet obtained was washed with PBS $(3 \times)$. The optical density of the cell suspension was set to 2.5 at $620 \mathrm{~nm}$. The cell mass was further treated with trypsin $(0.025 \%$, $\mathrm{w} / \mathrm{v}$ ), incubated at $37^{\circ} \mathrm{C}$ for $120 \mathrm{~min}$ and centrifuged $(3,000 \mathrm{rpm}$, $10 \mathrm{~min})$. The trypsinized cells were washed $(3 \times)$ with PBS prior to the analysis.

Haemagglutination activity was measured using intact as well as trypsinized human erythrocytes suspended in PBS. The protein $(5 \mathrm{pg}-50 \mu \mathrm{g})$ in PBS $(200 \mu \mathrm{l})$ was incubated with intact and trypsinized erythrocytes $(100 \mu \mathrm{l})$ in a 96-well micro titre plate for $120 \mathrm{~min}$ at $37^{\circ} \mathrm{C}$. The titre was observed visually, and the HAU was calculated using the lowest concentration of protein that agglutinated the erythrocytes.

\section{Antibody production and purification}

A female rabbit was immunized with $100 \mu \mathrm{g}$ of purified protein emulsified with $1 \mathrm{ml}$ of Freund's complete adjuvant. The protein was injected three times at an interval of 2 weeks in Freund's incomplete adjuvant. The animal was bled 3 weeks after the booster dose, and the antibodies were purified using a protein A-agarose column (26).

\section{Immunoblotting}

Protein was electrophoresed on an SDS-PAGE gel and electroblotted onto the PVDF membrane by the semidry blot method using a Tris-glycine buffer $(100 \mathrm{mM}, \mathrm{pH} 10)$. The blots were blocked overnight in $2 \%$ skimmed milk powder using Tris-buffered saline (TBS; $100 \mathrm{mM}, \mathrm{pH} \mathrm{10)}$ at room temperature (RT) and subsequently incubated with primary antibodies $(120 \mathrm{~min})$ in TBS-Tween-20 (TBST; $1 \%$ Tween-20, v/v) at $4{ }^{\circ} \mathrm{C}$. After washing $(3 \times$ at $5 \mathrm{~min})$ in TBST, the blots were incubated with goat anti-rabbit HRPconjugated secondary antibody in TBST buffer for $120 \mathrm{~min}$ at RT.
After three washes in TBST, the blots were developed using 3, $3^{\prime}$-diaminobenzidine and hydrogen peroxide $\left(\mathrm{H}_{2} \mathrm{O}_{2}\right)$.

\section{Immunocytochemistry}

Erythrocytes were washed with PBS and suspended in blocking solution $(2 \% \mathrm{BSA})$ for $120 \mathrm{~min}$. The cells were then washed in PBS, spread onto a cover slip and immediately fixed in $100 \%$ cold acetone. After $5 \mathrm{~min}$, the cover slips were washed extensively with PBS, and the fixed cells were incubated with BLG-col for $60 \mathrm{~min}$ at RT. The cells were washed again in PBS to remove the unbound protein and incubated with primary antibody (1:100) for $120 \mathrm{~min}$. After washing, the cover slips were incubated with secondary antibody [1:35, fluorescein isothiocyanate (FITC) labelled] for $60 \mathrm{~min}$. Finally, the cover slips were washed extensively with PBS, mounted in glycerine and sealed using DPX (27).

\section{Preparation of erythrocyte membrane}

Human blood was centrifuged $(4,400 \mathrm{rpm})$ at $4{ }^{\circ} \mathrm{C}$ for $10 \mathrm{~min}$ and the pellet was washed twice with PBS $\left(0.05 \mathrm{M} \mathrm{NaHPO}_{4}, 0.15 \mathrm{M} \mathrm{NaCl}\right.$, $\mathrm{pH}$ 8.0). Haemolysis was initiated by adding sodium phosphate buffer $(0.005 \mathrm{M}, \mathrm{pH} 8.0)$. The erythrocyte ghosts were pelleted by centrifugation $(15,000 \mathrm{rpm})$ at $4^{\circ} \mathrm{C}$ for $30 \mathrm{~min}$, and loosely packed ghosts were collected separately, discarding the hard pellet settled at the bottom. The ghosts were then suspended in PBS and stored at $4^{\circ} \mathrm{C}$.

\section{Results}

Isolation and characterization of BLG-col

The whey proteins isolated from colostrum were subjected for ammonium sulphate fractionation and the less heterogeneous supernatant fraction after $60 \%$ precipitation was subjected for purification on Sephadex G-100 (data not shown). Native PAGE confirmed the homogeneity of the purified protein and its exact molecular weight was determined by LC-ESI MS as 18.257 kDa (Fig. 1).

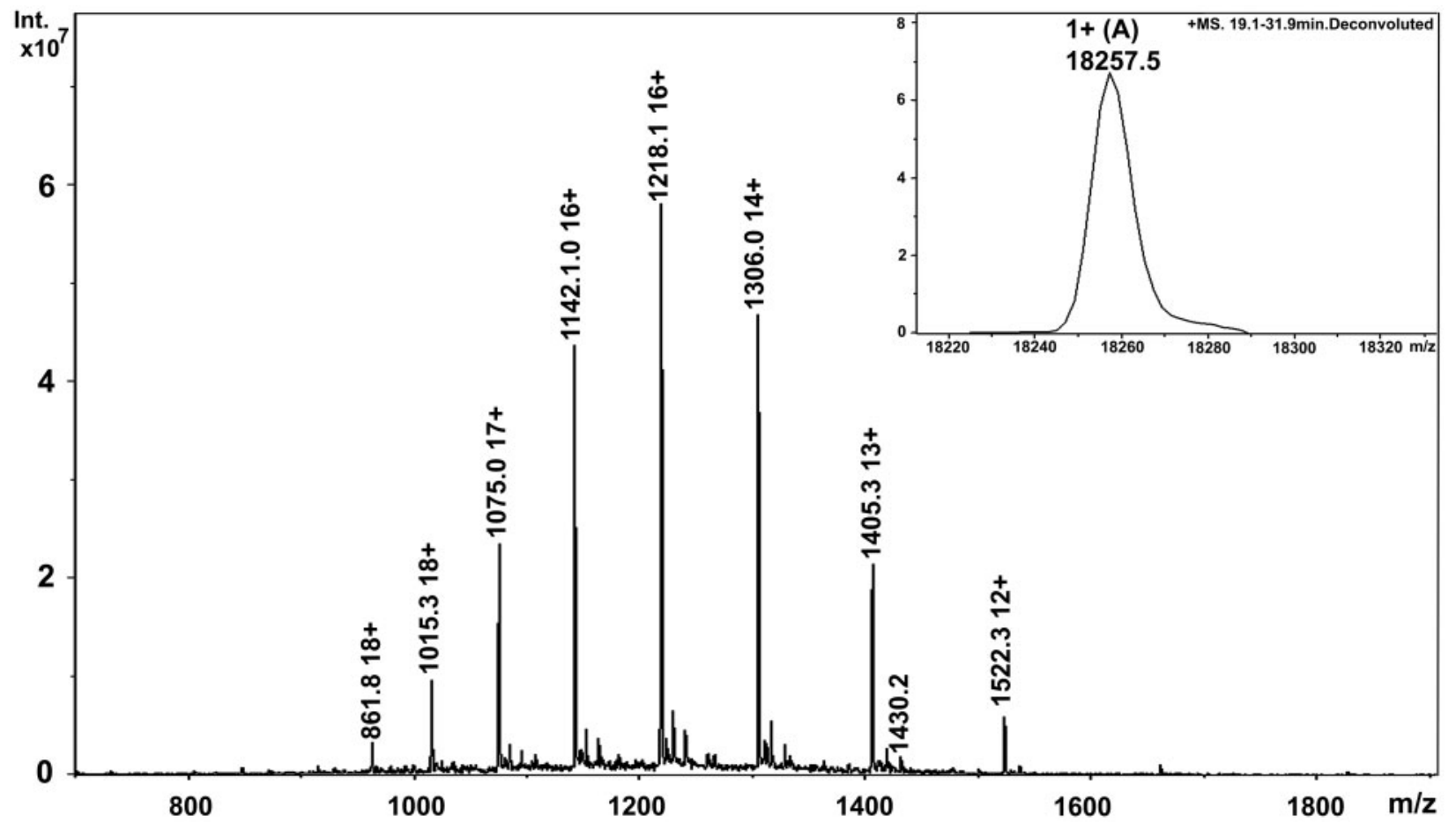

Fig. 1 Intact LC-ESI MS analysis of BLG-col using C-8 reverse-phase column $(4.6 \times 150 \mathrm{~mm}$; ZORBAX RX-C8, $5 \mu \mathrm{m}$, Agilent). Mass spectrum was acquired in positive ion mode by scanning $\boldsymbol{m} / z$-range from 400 to 2,800 . Deconvoluted mass of BLG-col is given in the inset. 


\section{Peptide mass fingerprinting}

The peptide mass fingerprint (PMF) of the purified protein was obtained after MALDI-TOF MS analysis (Fig. 2). The Mascot search result revealed the identity of the protein as BLG-col with $67 \%$ sequence homology to buffalo milk $\beta-\lg$, which belongs to lipocalin family of proteins (Supplementary File S1A and S1B).

\section{$\mathrm{NH}_{2}$-terminal analysis}

The $\mathrm{NH}_{2}$-terminal sequence analysis resulted in the five unambiguous residues I-I-V-T-Q, which agreed well with the MALDI-TOF sequence data of BLG-col (Supplementary File S1). The resultant sequence was aligned with $\beta$-lg of other ruminant and non-ruminant species for comparative analysis (Fig. 3). Interestingly, strong sequence homology was observed among the $\beta$-lg of buffalo, ovine, goat, rangifer and mouflon milk. However, BLG-col differed from bovine milk $\beta$-lg by containing an isoleucine instead of leucine at $\mathrm{NH}_{2}$-terminus, while partial identity was seen with the $\beta$-lg from pig milk at Positions 3 and 4 . But the $\mathrm{NH}_{2}$-terminal sequence of kangaroo and cat $\beta$-lg were entirely different from ruminant species (Fig. 3) including BLG-col.

\section{De novo sequencing of tryptic peptides}

The doubly charged ion pair of $m / z$ 2,313 detected after $31.2 \mathrm{~min}$ as $[\mathrm{M}+2 \mathrm{H}]^{2+} 1,156.8$ by LC-MS (Fig. 4) was subjected for LC-MS/MS analysis using CID/ETD tandem mass spectrometry containing radio frequency (rf) ion trap. The CID and ETD fragmentation (MS2) to cleave the peptide backbone to generate $\mathrm{b}$ and $\mathrm{y}$ ions for CID (Fig. 5A) and $\mathrm{c}$ and $\mathrm{z}$ ions for ETD (Fig. 5B) allowed for the identification of VYVEELKPTPEGDLEILLQK $($ Mr calcd = 2,312.25) sequence (Tables I and II: Supplementary File S2). The submission of .mgf file for protein identification in Mascot MS/MS ion search database confirmed the identity of sequence to $\beta$-lg (Supplementary File S3).
Furthermore, the sequence homology to buffalo and bovine milk $\beta$-lg was evidenced using NCBI BLAST search and was found in compliance to 41-60 amino acid sequence tag.

The triply charged ion, $m / z 546.2[\mathrm{M}+3 \mathrm{H}]^{3+}$ was detected after $32.4 \mathrm{~min}$ as by LC-MS (Fig. 3) corresponding to $m / z 1,636$ of PMF (Supplementary File S1). The CID (Fig. 6A) and ETD (Fig. 6B) fragmentation (MS2) generated product ions allowed for the identification of TPEVDDEALEKFDK (Mr calcd =1,634.76) sequence (Tables III and IV: Supplementary File S4). The submission of .mgf file to Mascot MS/MS ion search database further confirmed the identity of sequence to $\beta-\lg$ (Supplementary File S5). Furthermore, the sequence homology to buffalo and bovine milk $\beta$-lg

\section{CLUSTAL 2.0.12 Multiple sequence alignment}

$\begin{array}{lcc}\text { Kangaroo-BLG } & \text { VENIR- } & 5 \\ \text { Horse-BLG } & \text {-TNIPQ } & 5 \\ \text { Goat-BLG_Precursor } & \text {-IIVTQ } & 5 \\ \text { Mauflon-BLG } & \text {-IIVTQ } & 5 \\ \text { Mauflon-BLG } & \text {-IIVTQ } & 5 \\ \text { Ovis_sp-BLG } & \text {-IIVTQ } & 5 \\ \text { Ragnifer-BLG } & \text {-IIVTQ } & 5 \\ \text { Ovis_aries-BLG } & \text {-IIVTQ } & 5 \\ \text { Buffalo-BLG_mRNA } & \text {-IIVTQ } & 5 \\ \text { Buffalo-BLG_col_* } & \text {-IIVTQ } & 5 \\ \text { Bovine-BLG } & \text {-LIVTQ } & 5 \\ \text { Bovine-BLG_mtantYES } & \text {-LIVTQ } & 5 \\ \text { Bovine-BLG_Precursor } & \text {-LIVTQ } & 5 \\ \text { Pig-BLG } & \text {-VEVTQ } & 5 \\ \text { Cat-BLG } & \text {-ATLPP } & 5\end{array}$

Fig. 3 Multiple sequence alignment of BLG-col using ClustalW2 online server with the ruminant and other mammalian species (http:// www.ebi.ac.uk/Tools/msa/clustalw2/).

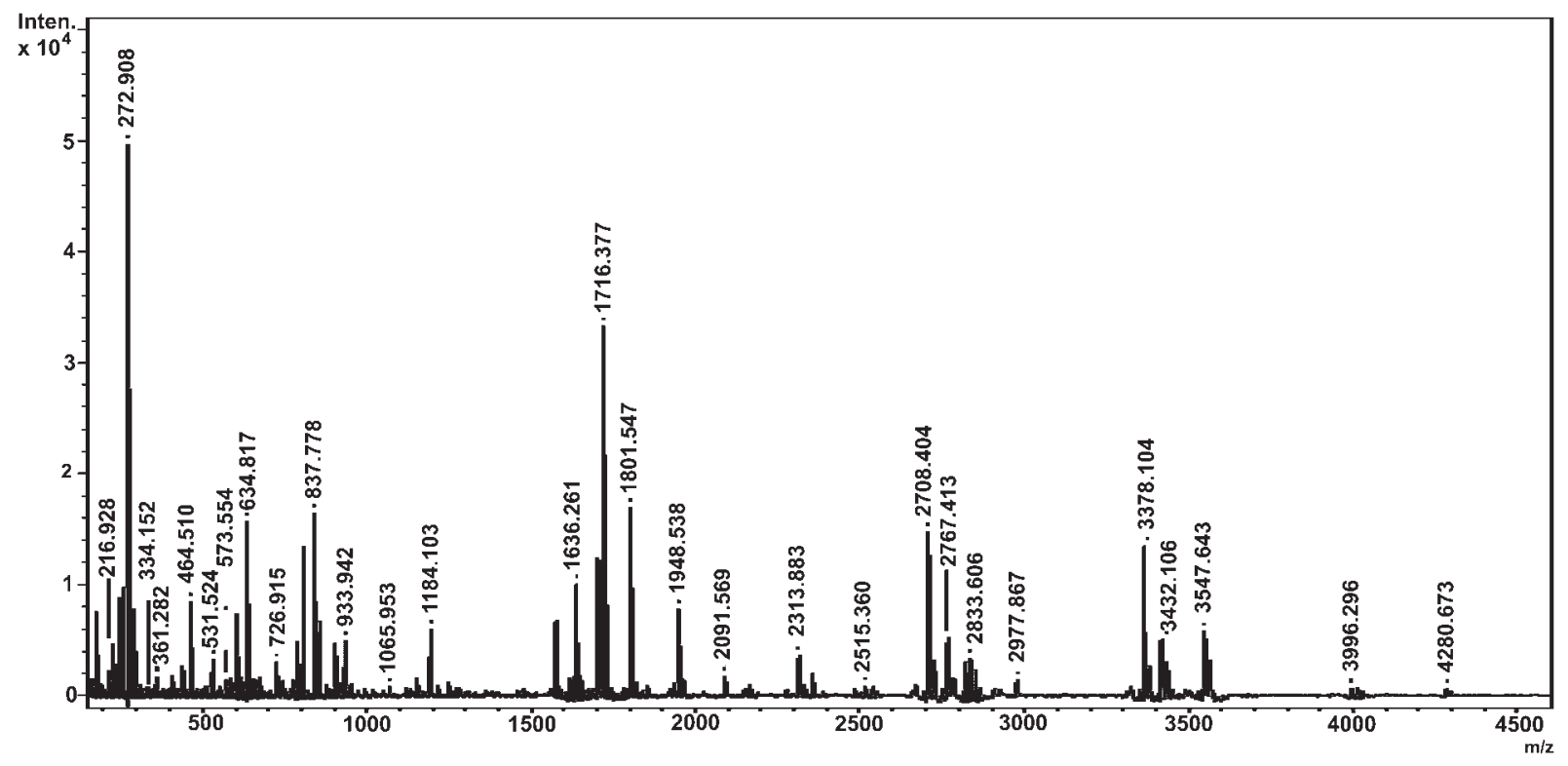

Fig. 2 The PMF of the purified protein obtained after MALDI-TOF MS analysis. 


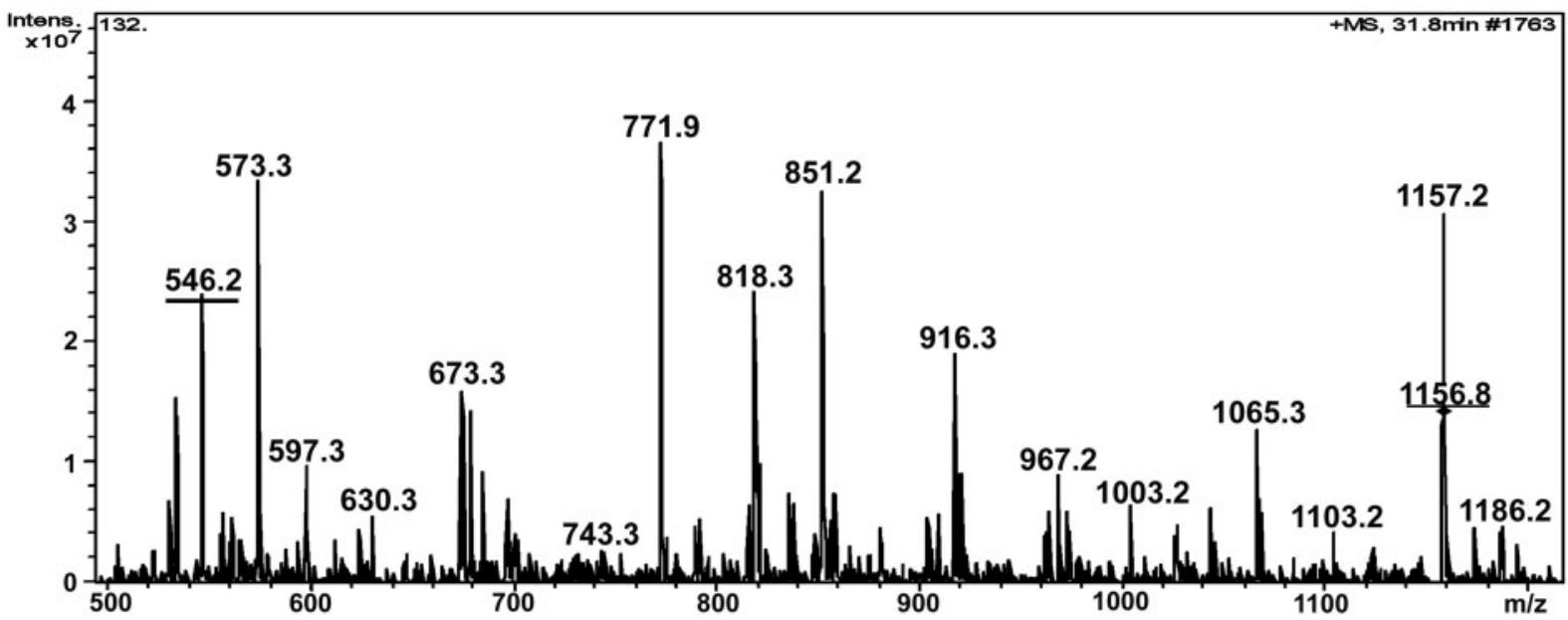

Fig. 4 LC-MS analysis of tryptic peptides derived from the BLG-col showing doubly and triply charged precursor ions $[\mathrm{M}+3 \mathrm{H}]^{3+} \mathbf{5 4 6 . 2}$ and $[\mathrm{M}+2 \mathrm{H}]^{2+} \mathbf{1 , 1 5 6 . 0}$.

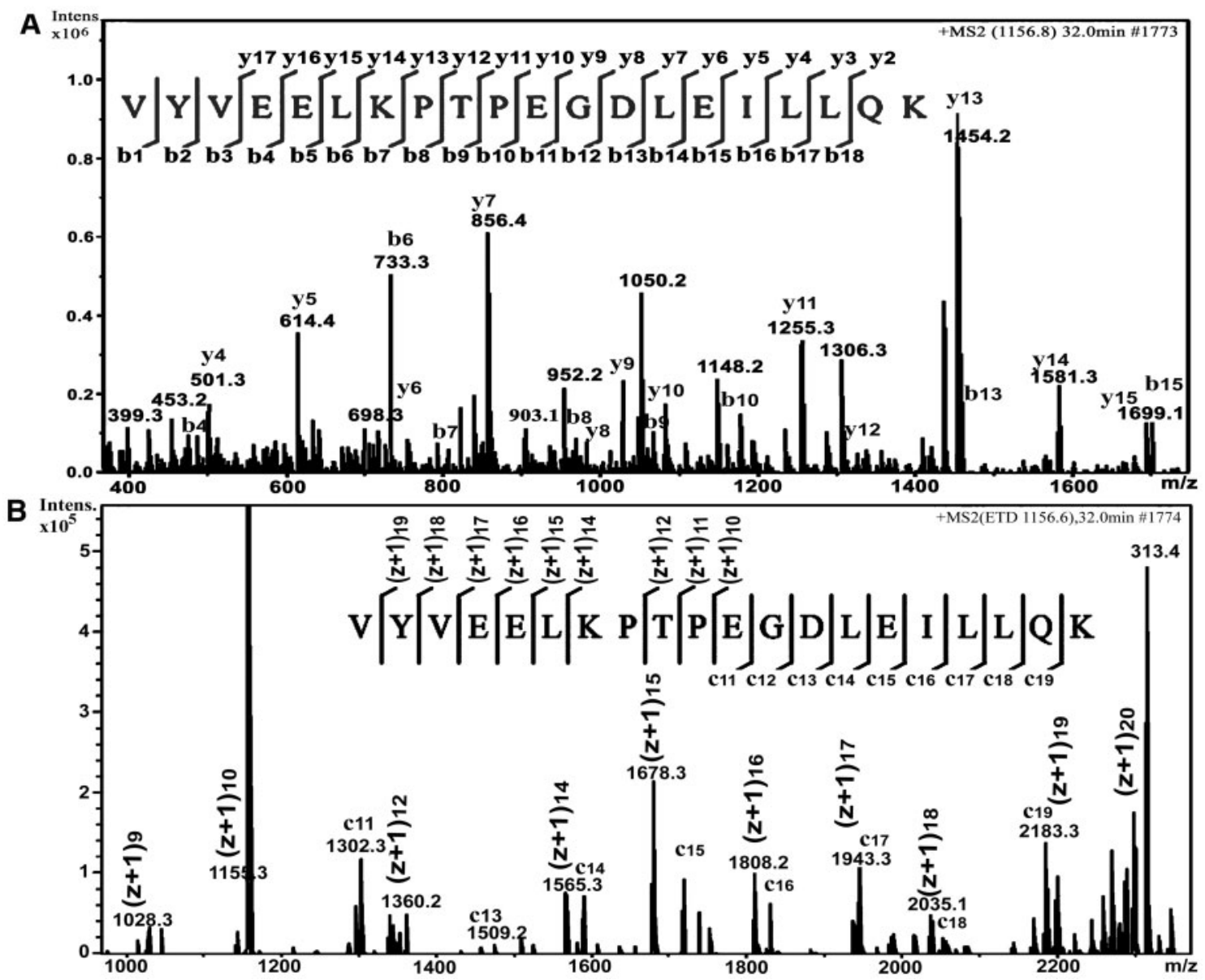

Fig. 5 LC-ESI-CID/ETD MS/MS analysis of precursor ion $\boldsymbol{m} / \boldsymbol{z}$ 2,313. (A) CID spectrum of doubly charged ion $[\mathrm{M}+2 \mathrm{H}]^{2+} 1,156.0 \mathrm{observed}$ at $32 \mathrm{~min}$. The $\mathrm{b}$ and $\mathrm{y}$ ion series are shown together with the deduced sequence. (B) ETD spectrum of doubly charged ion $[\mathrm{M}+2 \mathrm{H}]^{2+} 1,156.0$ observed at $32 \mathrm{~min}$. The $\mathrm{c}$ and $\mathrm{z}$ ion series are shown together with the deduced sequence.

was evidenced using NCBI BLAST search with perfect match to 125-138 amino acid sequence tag.

Hence de novo sequencing of doubly and triply charged ions confirmed BLG-col in analogy to the
PMF data. Using the sequence information generated by CID and ETD, we could localize BLG-col gene on chromosome 11 at loci 11q28 on bovine genome using NCBI blast search (Supplementary Files S6 and S7). 


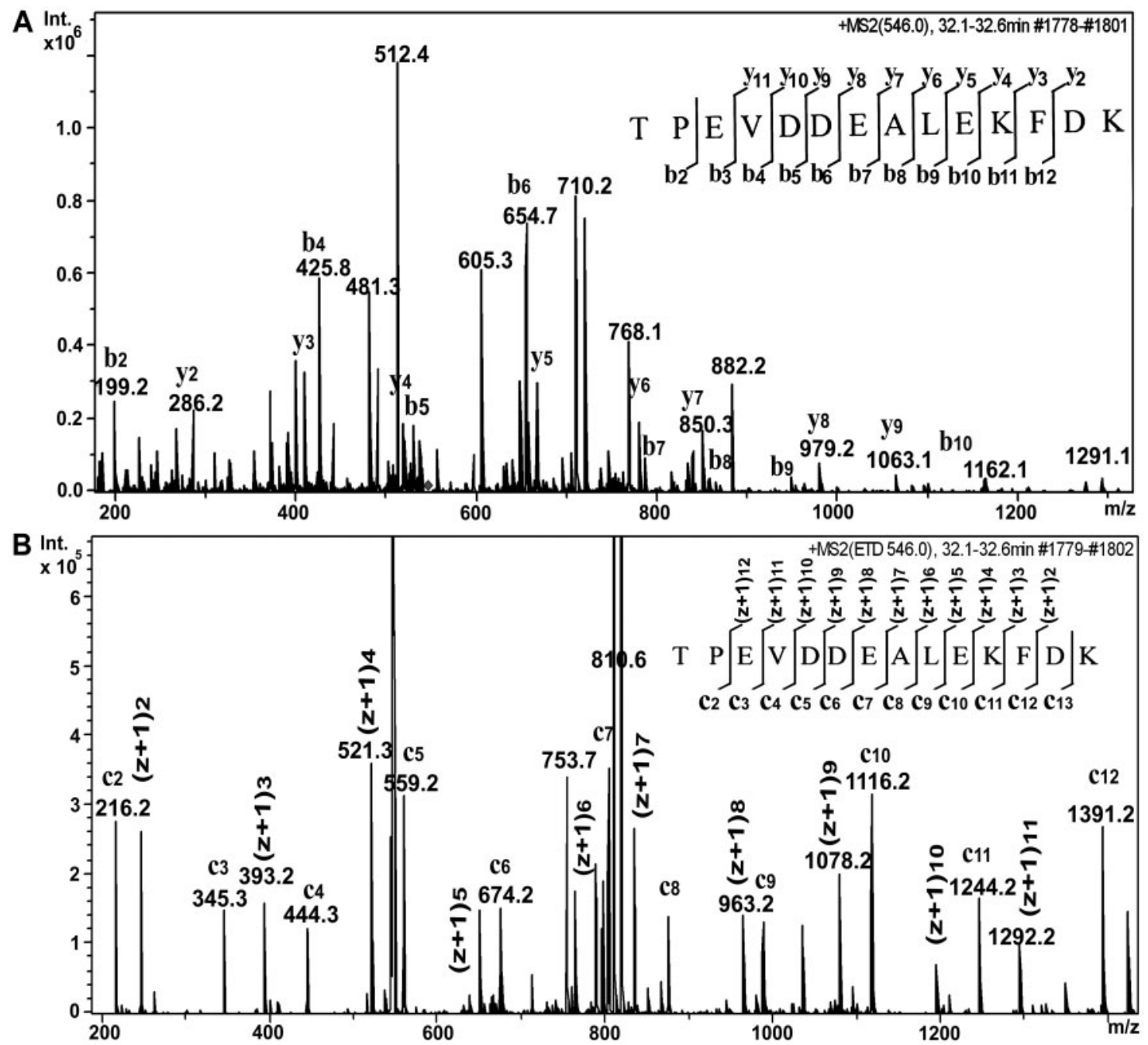

Fig. 6 LC-ESI-CID/ETD MS/MS analysis of precursor ion $\boldsymbol{m} / \boldsymbol{z} \mathbf{1 , 6 3 6}$. (A) CID spectrum of triply charged ion $[\mathrm{M}+3 \mathrm{H}]^{3+} 546.2$ observed at 32.4 min. The $\mathrm{b}$ and $\mathrm{y}$ ion series are shown together with the deduced sequence. (B) ETD spectrum of triply charged ion $[\mathrm{M}+3 \mathrm{H}]^{3+} 546.2$ observed at $32.4 \mathrm{~min}$. The $\mathrm{c}$ and $\mathrm{z}$ ion series are shown together with the deduced sequence.

\section{Antigenicity and HAU of BLG-col}

The antibodies raised to BLG-col exhibited its antigenic nature as confirmed by western blot analysis (Fig. 7). Furthermore, the antibody was also found reactive to bovine milk $\beta$-lg. The interaction of BLG-col was investigated with human erythrocytes and accordingly, BLG-col displayed HAU against 'A', 'B' and 'O' blood groups (Fig. 8A). A strong agglutination was recorded with the 'O' (10,309 HAU/mg) compared to 'A' $(1,280 \mathrm{HAU} / \mathrm{mg})$ and 'B' (320 HAU/mg) blood groups with trypsinized erythrocytes. A similar pattern was even observed in intact erythrocytes $(3,205 \mathrm{HAU} / \mathrm{mg}$ in 'O', $800 \mathrm{HAU} / \mathrm{mg}$ in 'A' and $200 \mathrm{HAU} / \mathrm{mg}$ in 'B').

\section{Immunocytochemistry of BLG-col}

The interaction of BLG-col with erythrocytes was further confirmed by immunochemistry using FITClabelled secondary antibody. As shown in Fig. 8B, the cell surface localization of BLG-col was evidenced on all the blood groups tested. Since the HAU was significantly high in blood group ' $\mathrm{O}$ ' compared to either ' $\mathrm{A}$ ' or ' $\mathrm{B}$ ', the erythrocyte ghosts were prepared from ' $\mathrm{O}$ ' group to identify the lipocalin interacting membrane protein.

\section{Identification of receptor protein by immunoblot analysis}

The erythrocyte ghosts were solubilized in the nondenaturing buffer and separated on SDS-PAGE $(12 \%)$. The immunoblot analysis of the separated proteins with BLG-col antibody clearly revealed the presence of lipocalin receptor protein and its molecular mass was found to be $70 \mathrm{kDa}$ (Fig. 9). The same protein band was then excised from the gel and subjected for in gel trypsin digestion for PMF analysis.

\section{Peptide map for LIMR}

The PMF of the LIMR of erythrocytes was obtained by MALDI-TOF analysis and PROWL peptide map database search revealed $8 \%$ sequence homology to limb region 1 protein homologue (LMBR1_HUMAN, Q8WVP7), which belongs to lipocalin transmembrane receptor protein (Fig. 10). In order to establish sequence homology among LIMR 
proteins, multiple sequence alignment of the known lipocalin receptors was carried out using ClustalW2. Interestingly, the match showed very little sequence homology indicating diversity among LIMR proteins.

\section{Discussion}

Recent investigations recognized that toddlers having allergy to cow milk posses tolerance to water buffalo milk. Hence, clinical studies are underway to determine whether water buffalo milk shall be a promising alternative food for the children having

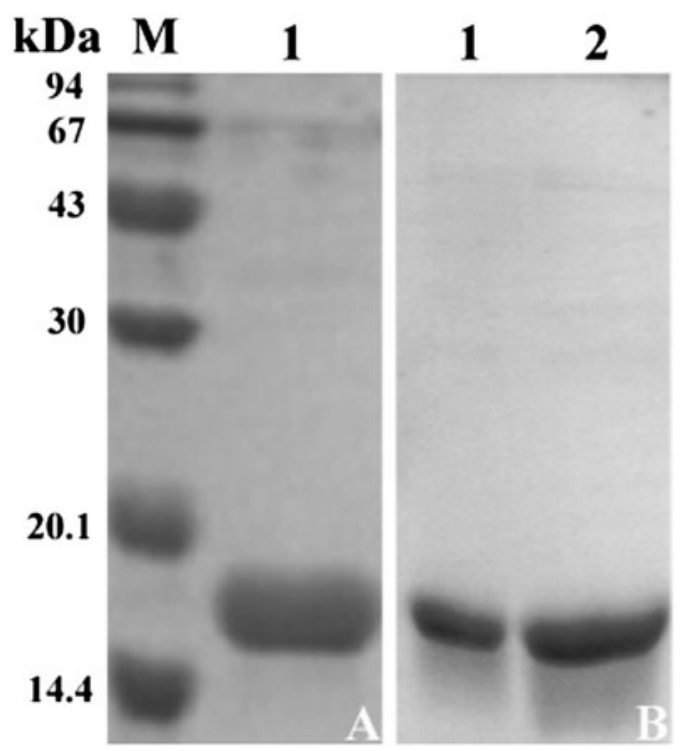

Fig. 7 SDS and immunoblot analysis of BLG-col. (A) Protein electrophoresed on SDS-PAGE. (B) The SDS-PAGE gel was transferred on PVDF membrane by the semidry blot method and processed using Primary antibody $(1: 2,000)$ and secondary antibody $(1: 1,000)$ conjugated with HRP. Lane 1B. BLG-col and Lane 2B. Bovine milk $\beta$-lg. cow milk allergy (28). Considering the therapeutic importance of buffalo milk, which is a major milking mammal in Asia, we have adapted advanced proteomic techniques for purification and characterization of a novel protein BLG-col from buffalo colostrum and to uncover its functional property.

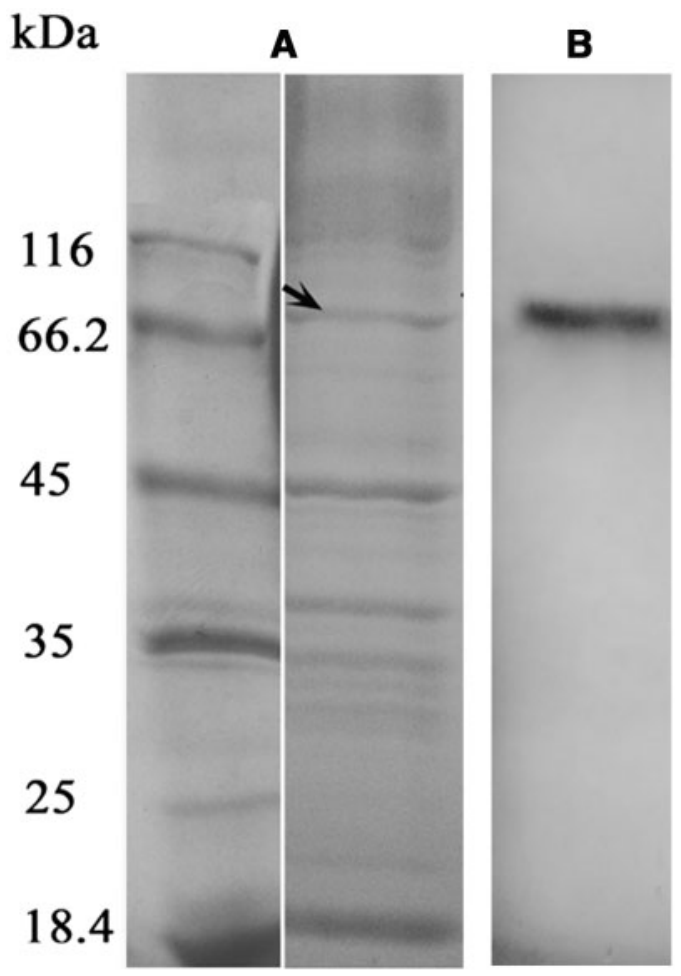

Fig. 9 Electrophoretic analysis of LIMR. (A) SDS-PAGE of erythrocyte membrane proteins. (B) Western blot analysis using anti-BLG-col antibody raised in rabbit and goat anti-rabbit secondary antibody conjugated with HRP.

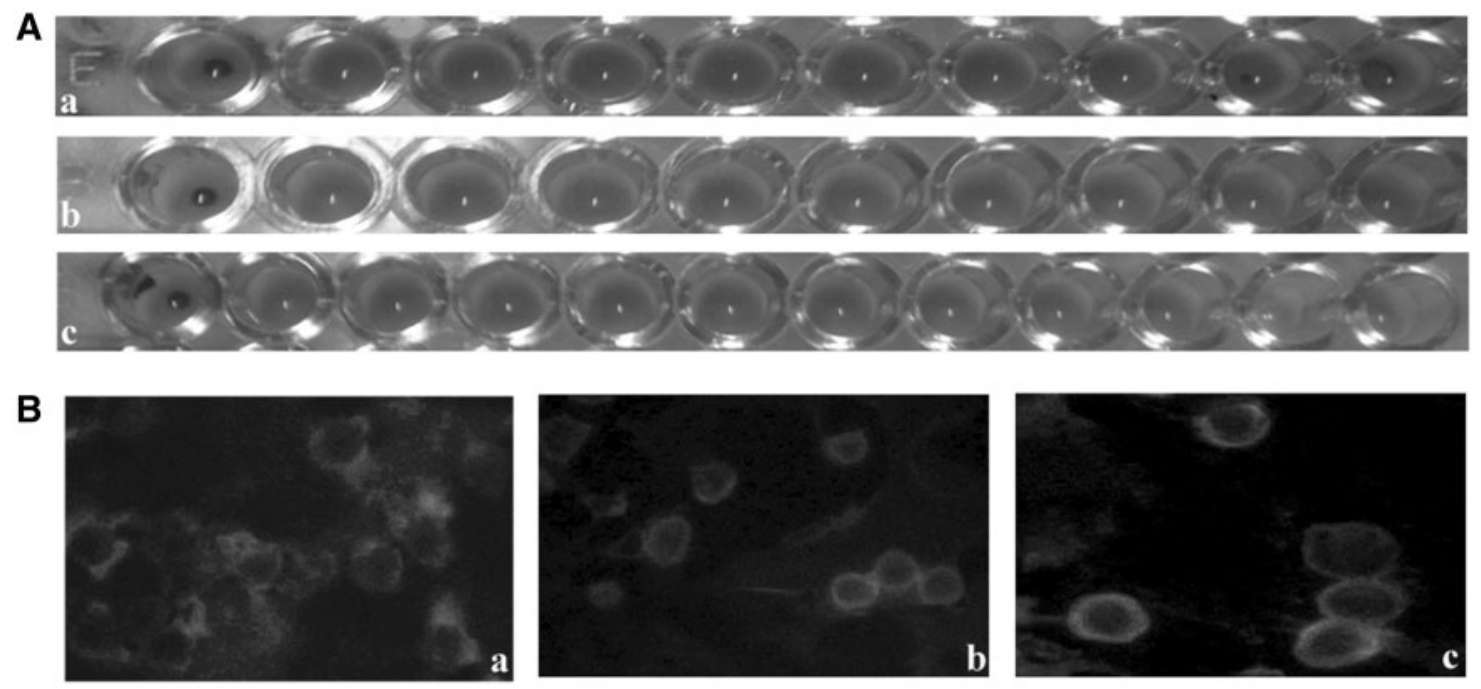

Fig. 8 Hemagglutination and Immunolocalization studies. (A) Hemagglutination assay: BLG-col (5 pg $50 \mathrm{mg}$ ) was incubated with intact and trypsinized erythrocytes in a 96-well micro titre plate at $37^{\circ} \mathrm{C}$. (B) Immunolocalization of BLG-col on erythrocyte membrane. The human erythrocytes were incubated with BLG-col followed by primary antibody (1:100) and FITC-conjugated goat anti-rabbit secondary antibody (1:35).The images were captured in Fluorescent microscope. (a) Blood group 'A', (b) Blood group 'B' and (c) Blood group 'O'. 


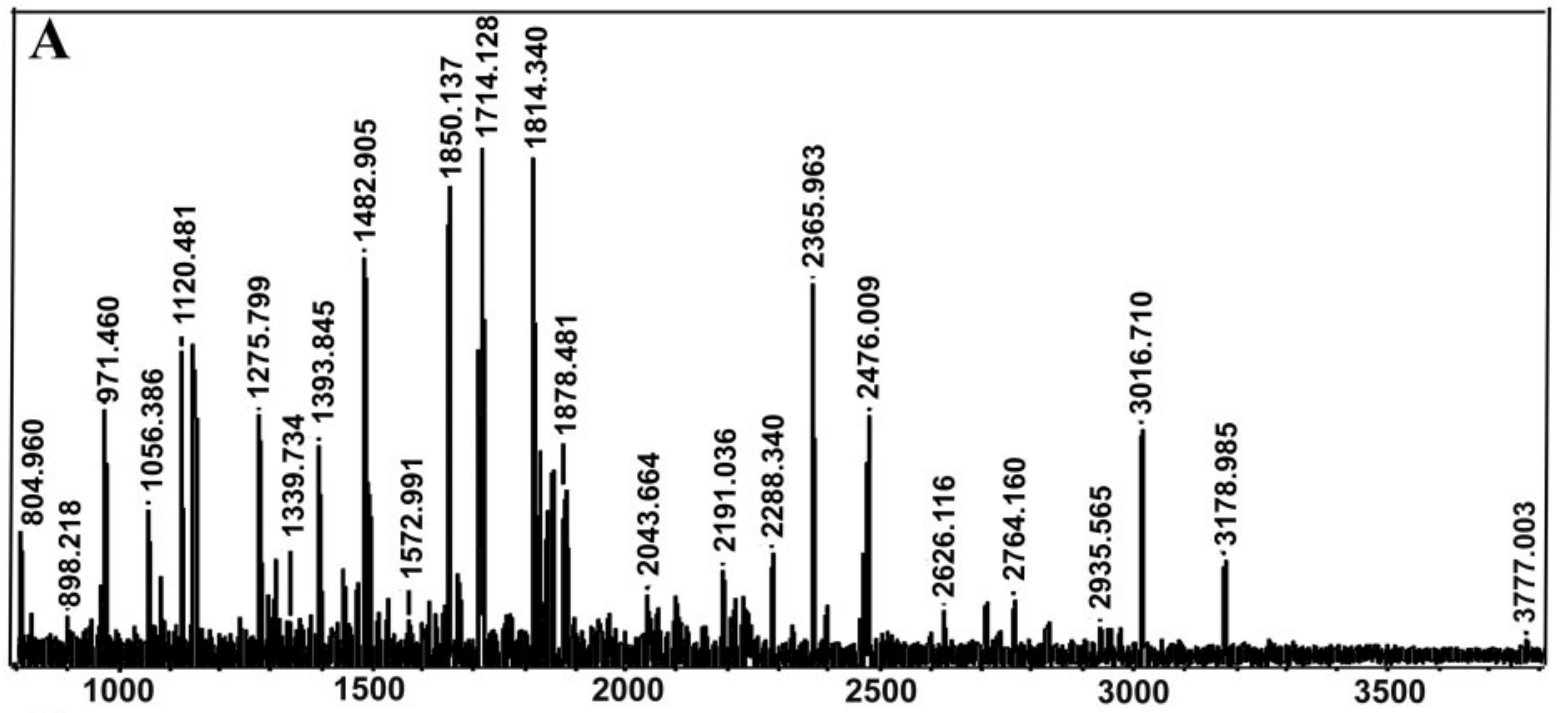

B

Name: Q8WVP7 (LMBR1_HUMAN)

Number of Measured Peptides: 101

Number of Matched Peptides : 5

Min. Coverage of Sequence : $8 \%$

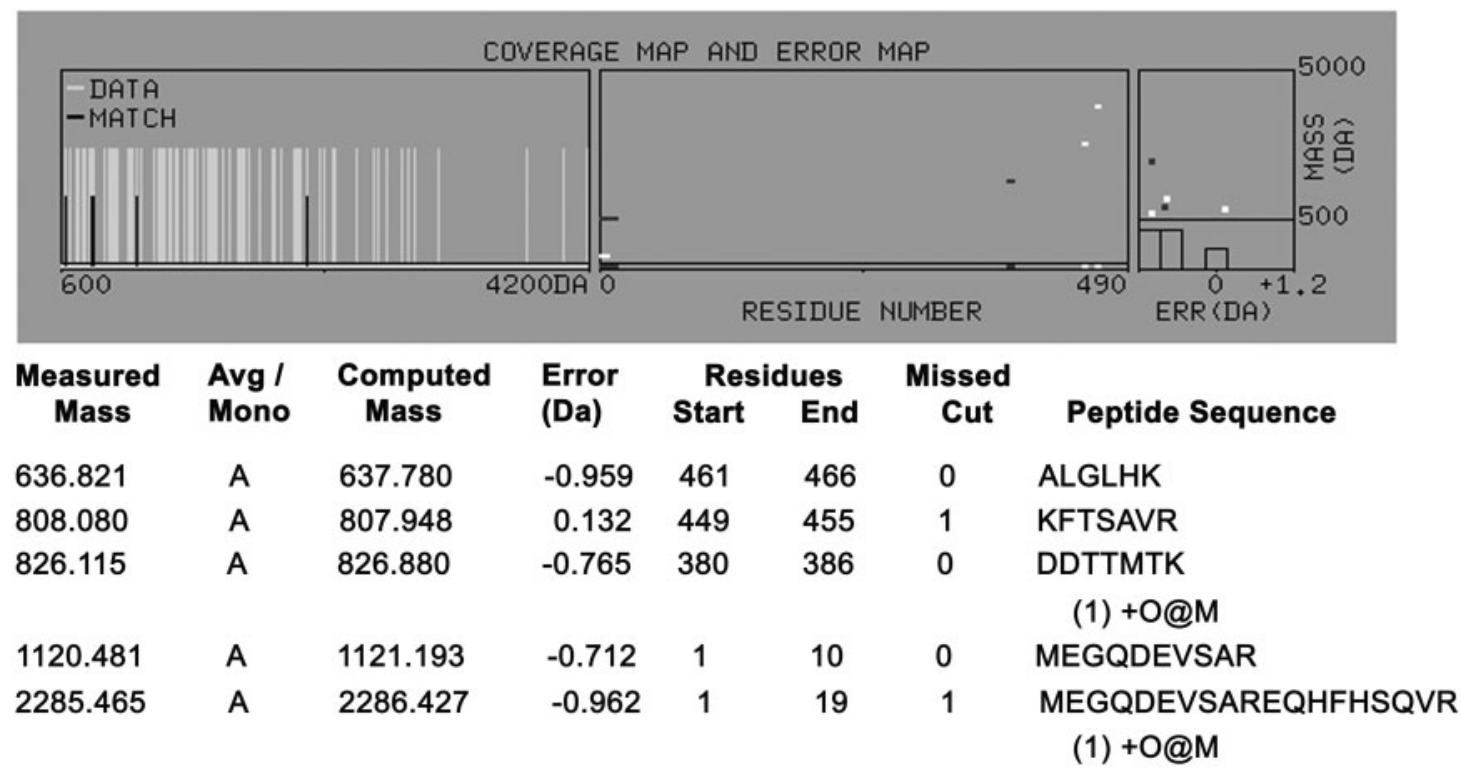

Fig. 10 MALDI-TOF MS analysis of LIMR. (A) Peptide mass fingerprint of BLG-col-interacting erythrocyte membrane receptor. (B) Identification and peptide mapping analysis of BLG-col-interacting receptor using PROWL database.

In the present study, BLG-col $(18.257 \mathrm{kDa})$ purified from buffalo colostrum revealed $67 \%$ sequence coverage to milk and cDNA of water buffalo $\beta$-lg, which was supported by both N-terminal and LC-ESI-CID/ ETD MS/MS analyses. The N-terminal sequence of BLG-col showed complete homology to the $\beta$-lg from buffalo, ovine, goat and mouflon milk, while a single amino acid variation at amino terminus of bovine was obvious, which is likely to be of no physiological relevance. But all the five residues derived from the $\mathrm{N}$-terminal sequence closely matched the sequence derived from the PMF of the purified protein, which confirms the identity of the purified protein. The significant similarity of BLG-col to buffalo milk $\beta$-lg observed supports large-scale production of 'high value' and 'low volume' proteins of neutraceutical importance.

Towards the functional properties, the antibodies of BLG-col showed positive reactivity to BLG-col and also to both buffalo and bovine milk $\beta$-lg. The reactivity thus indicated the possibility of similar epitopes being shared by milk and colostrum BLG-col and also proved its antigenic nature in analogy to the $\beta$-lg isolated from buffalo milk (22) in support of the structural homology established in the present investigation. Although $\beta$-lg derived from bovine milk is 
attributed to have antioxidant property (29), the haemagglutinating activity of BLG-col was performed for the first time using human erythrocytes. Notably, agglutination of BLG-col was observed both in native and trypsinized erythrocytes with higher order of interaction in ' $\mathrm{O}$ ' compared to ' $\mathrm{A}$ ' and ' $\mathrm{B}$ ' blood groups. Incidentally, our earlier investigations had also revealed presence of antigenic glycopeptide exhibiting blood group ' $\mathrm{B}$ ' specificity (6) in buffalo colostrum. Hence, the preferential haemagglutinating property of BLG-col envisages its significance in blood group typing due to its specific glycan binding property, which is a unique finding of the present investigation. To further substantiate, BLG-col was found localized on the cell surface of erythrocytes as evidenced by immunolocalization studies suggesting the possible occurrence of receptors for BLG-col on human erythrocytes.

To date, information on the isolation, identification and characterization of receptors that mediate cellular uptake of lipocalins and their ligands is limited. The well-studied receptors include classical lipocalin RBP and megalin (30). The cell surface receptor STRA6 that transports retinol across the plasma membrane gets stimulated in the presence of retinol, and immunolocalization studies revealed strong expression of STRA6 on the basolateral membrane of retinal pigment epithelial cells (31). Similarly, megalin being an endocytic receptor binds wide variety of ligands, including RBP, major urinary protein, thyroglobulin, apolipoprotein $\mathrm{A}$, albumin, insulin and olfactory binding protein (31). Although receptors for $\beta$-lg have been identified on the neonatal intestine, bovine plasma membrane and also on transformed cells (17), there are no reports on their characterization so far. The immunoblot analysis performed with the membrane lysate of human erythrocytes in the present study not only supported immunolocalization studies and the identification of $70 \mathrm{kDa}$ interacting membrane protein but also suggested possible occurrence of LIMR for BLG-col on human erythrocytes. Further, in analogy to the earlier observations, the PMF match of receptor protein showed no consensus among the identified receptor structures, suggesting a great diversity in lipocalin receptors (32). The present study thus represents the first report to show the presence of LIMR on human erythrocytes. Although $\beta-1 g$ is implicated in the transport of vitamin $\mathrm{D}$, since physiological ligand not being known, no conclusions can be drawn on the biological function of lipocalin receptor on erythrocytes. Further, as humans do not possess $\beta$-lg gene, the localization of BLG-col on erythrocytes remains enigmatic.

Since lipocalins have drawn considerable attention in health and disease (33), our investigations can have important consequences in the isolation and characterization of an abundant lipocalin from whey and identifying its novel receptor. The development of a simple strategy for the purification of BLG-col from buffalo colostrum and assigning newer role of haemagglutinating property seems to be interesting. The immunolocalization and characterization of lipocalin receptor on erythrocytes draws attention to envisage the newer role of BLG-col.

\section{Supplementary Data}

Supplementary Data are available at $J B$ online.

\section{Acknowledgements}

We thank University Grant Commission, New Delhi, India for sanction of grant (F31-294/2005-06) to undertake this investigation and Rohit A. Chougule thank Indian Council of Medical Research, New Delhi for grant of Senior Research Fellowship (45/12/2009Biochemistry/BMS).

\section{Conflict of interest}

None declared.

\section{References}

1. Urashima, T., Saito, T., Nakamura, T., and Messer, M. (2001) Oligosaccharides of milk and colostrums in non-human mammals. Glycoconj. J. 18, 357-371

2. Uruakpa, F.O., Ismond, M.A.H., and Akobundu, E.N.T. (2002) Colostrum and its benefits: a review. Nutr. Res. 22, 755-767

3. Colarow, L., Turini, M., Tencberg, S., and Berger, A. (2003) Characterization and biological activity of gangliosides in buffalo milk. Biochim. Biophys. Acta. 1631, 94-106

4. Kotresh, A.M. (2009) Structural features of the 5 '-franking region of the $\beta$-lactoglobulin gene of buffalo (Bubalus bubalis). Buffalo Bull. 28, 34-39

5. Blanc, B. (1981) Biochemical aspects of human milk-comparison with bovine milk. World Rev. Nutr. Diet 36, 1-89

6. Aparna, H.S. and Salimath, P.V. (2001) Purification of an Antigenic Glycopeptide from buffalo colostrum. J. Food Sci. Technol. 38, 450-452

7. Aparna, H.S. and Salimath, P.V. (1994) Galactose terminated oligosaccharides activate macrophage respiratory burst. Nutr. Res. 14, 433-444

8. Aparna, H.S. and Salimath, P.V. (1999) Studies on the acidic glycoproteins of buffalo colostrum and their influence on the growth of Bifidobacterium bifidus. Nutr. Res. 19, 295-303

9. Otani, H. and Hata, I. (1995) Inhibition of proliferative response of mouse spleen lymphocytes and rabbit Peyer's patch cells by bovine milk caseins and their digests. J. Dairy Res. 62, 339-348

10. Otani, H., Monnai, M., Kawasaki, Y., and Kawakami, H. (1995) Inhibition of mitogen-induced proliferative responses of lymphocyte by bovine $\kappa$-caseinoglycopeptides having different carbohydrate chains. J. Dairy Res. 62, 349-357

11. Flower, D.R., North, A.C.T., and Sansom, C.E. (2003) The lipocalin protein family-structure and sequence overview. Biochim. Biophys. Acta. 1482, 9-24

12. Sawyer, L. and Kontopidis, G. (2000) The core lipocalin bovine $\beta$-lactoglobulin. Biochem. Biophys. Acta. 1482, $136-148$

13. Yang, M.C., Chen, N.C., Chen, C.J., Wu, C.Y., and Mao, S.J. (2009) Evidence for beta-lactoglobulin involvement in vitamin D transport in vivo-role of the gamma-turn (Leu-Pro-Met) of beta-lactoglobulin in vitamin D binding. FEBS J. 276, 2251-2265 
14. Hernandez-Ledesma, B., Recio, I., and Amigo, L. (2008) $\beta$-lactoglobulin as source of bioactive peptides: Review article. Amino Acids 35, 257-265

15. Korhonen, H. and Pihlanto, A. (2006) Bioactive peptides: production and functionality. Int. Dairy J. 16, 945-960

16. Hannu, K., Riitta, K., Markkku, S., Tatiana, V.B., Yvan, C., and Thomas, H. (1999) Glycodelin and $\beta$-lactoglobulin, lipocalins with a high structural similarity, differ in ligand binding properties. FEBS Lett. 450, $158-162$

17. Palupi, N.S., Franck, P., Guimont, C., Linden, G., Dumas, D., Stoltz, J., Nabet, P., Belleville-Nabet, F., and Dousset, B. (2000) Bovine $\beta$-lactoglobulin receptors on transformed mammalian cells (hybridomas MARK-3): characterization by flow cytometry. J. Biotechnol. 78, 171-184

18. Fluckinger, M., Merschak, P., Hermann, M., Haertlé, T., and Redl, B. (2008) Lipocalin-interacting-membranereceptor (LIMR) mediates cellular internalization of $\beta$-lactoglobulin. Biochim. Biophys. Acta.- Biomembranes 1778, 342-347

19. Vyas, H.K., Izco, J.M., and Jimenez-Flores. (2002) Scale up of native $\beta$-lactoglobulin affinity separation process. J. Dairy Sci. 85, 1639-1645

20. Preaux, G., Braunitzer, G., and Kolde, H. (1980) Primary structure of ovine beta-lactoglobulin. J. Arch. Int. Physiol. Biochim. 88, B45-B46

21. Preaux, G., Braunitzer, G., Schrank, B., and Stangl, A. (1979) The amino acid sequence of goat betalactoglobulin. Hoppe-Seyler's Z. Physiol. Chem. 360, 1595-1604

22. Li, X., Luo, Z.L., Chen, H.B., and Cao, Y.S. (2008) Isolation and antigenicity evaluation of $\beta$-lactoglobulin from buffalo milk. Afr. J. Biotechnol. 13, 2258-2264

23. Chang, J.Y. (1983) Manual micro sequence analysis of peptides using dimethyl aminobenzene isothiocyanate. Methods Enzymol. 91, 455-466
24. Rosenfeld, J., Capdevielle, J., Guillemot, C., and Ferrara, P. (1992) In-gel digestion for internal sequence analysis after one-or two-dimensional gel electrophoresis. Anal. Biochem. 203, 173-179

25. Wu, S.L., Huhmer, A.F., Hao, Z., and Karger, B.L. (2007) On-line LC-MS approach combining collisioninduced dissociation (CID), electron-transfer dissociation (ETD), and CID of an isolated charge-reduced species for the trace-level characterization of proteins with post translational characterization. J. Proteome Res. 6, 4230-4244

26. Vaitukaitis, J.L. (1981) Production of antisera to small doses of immunogen: multiple intradermal injections. Methods Enzymol. 73, 46-57

27. Petra, W., Markus, L., Petra, M., and Bernhard, R. (2001) Molecular cloning of a novel lipocalin-1 interacting Human cell membrane receptor using phage display. J. Biolchem. 276, 20206-20212

28. Willam, J.S. and Wanda, P. (2009) Tolerance to water buffalo milk in a child with cow milk allergy. Ann. Allergy Asthma Immunol. 102, 349-350

29. Liu, H.C., Chen, W.L., and Mao, S.J.T. (2006) Antioxidant nature of bovine milk $\beta$-lactoglobulin. J. Dairy Sci. 90, 547-555

30. Hvidberga, V., Jacobsena, C., Strongb, R.K., Cowlandc, J.B., Moestrupa, S.K., and Borregaardc, N. (2005) The endocytic receptor megalin binds the iron transporting neutrophil-gelatinase-associated lipocalin with high affinity and mediates its cellular uptake. FEBS Lett. 579, 773-777

31. William, S.B. (2007) STRA6, a cell surface receptor for retinol-binding protein: the plot thickens. Cell Metab. 5, 164-166

32. Flower, D.R. (2000) Beyond the superfamily: the lipocalin receptors. Biochim. Biophys. Acta 1482, 327-336

33. Schlehubera, S. and Skerra, A. (2005) Review: lipocalins in drug discovery: from natural ligandbinding proteins to 'anticalins'. Drug Discov. Today 10, 23-33 